\title{
Spring Branch Updates
}

\author{
Alberta Branch \\ Jason MacDonald, CPHI(C) \\ President, CIPHI Alberta Branch
}

2012 brings another busy year for the Alberta Branch. While I write this, our province is immersed in a contentious battle for leadership and changes are thought to be looming. Of course, while the provincial leadership battle rages on, we also have members closely watching the recent Federal staffing changes and others who recently were asked to ratify a new collective bargaining agreement. Needless to say, politics are on the mind of our members at this time.

On a lighter note, the annual Alberta Branch NHL regular season hockey pool came to a close with Quentin Schatz of Red Deer taking home the grand prize. The pool continues to engage many members of the Branch and you can often hear lively discussion about it beside various water coolers in the Province.

This June will be both enjoyable and productive. Our Annual General Meeting (AGM) will take place in Red Deer on June 9 and our Executive is currently reviewing our bylaws to see if any changes need to be brought forward to the membership. Coupled with our AGM is our annual golf tournament down the highway in lovely Sylvan Lake. The tournament is on June 10 and promises to be fun for members and their families. Sylvan Lake, Alberta, a jewel for many occasions, makes an ideal location for this AGM/tournament weekend. In fact, the town will be celebrating their annual 1913 Days. For anyone who might want to make it a family trip to Sylvan Lake for that weekend, check our website for details on our planned social events and on how to register for the golf tournament. We would love to see you there.

This July concludes our 40th year as CIPHI Alberta Branch. One of the great initiatives that began this last year was the creation of our Historical Committee. With an eye on 2013, the committee is diligently reviewing our archives for treasures from the past. Our Branch is fortunate to have maintained an interesting and comprehensive record, so we look forward to sharing our history with you in 2013.

We will celebrate Environmental Public Health Week this September by hosting our 13th Annual Fall Educational Workshop. The event will take place on September 26 and 27 in Edmonton at the glorious Fantasyland Hotel. Our mission with this workshop is to generate awareness and confidence within our membership about our roles as employees, community citizens, professionals and family members when it comes to preparedness for, and response to, emergencies. I look forward to updating you all in the next update on more specifics related to our workshop.
I hope you all enjoy this edition of the Environmental Health Review. On behalf of our members and Branch Executive, we hope you all have a great spring!

\section{British Columbia Branch \\ Gary Tam, BSc, B.Tech, CPHI(C) President, CIPHI BC Branch}

While the Vancouver Canucks are already thinking about booking their golfing trips for their off-season (note: this article was written as LA led Vancouver 3-0 in the series), our BC Branch executives have been busy organizing a twoday educational conference. Once again, we are going to work with the National Collaborating Center for Environmental Health to develop a topic-focused conference for our members. In other news, our Past President, Mr. Keir Cordner, has committed to being the chair of a newly established BC Branch CIPHI Centenary Celebration Committee to coordinate different celebration activities. We are fortunate that the committee was formed with various levels of membership, including Life, Retired, Regular and Student, which can provide comprehensive historical coverage on the BCIT Environmental Health Program, CIPHI - BC Branch, and the Environmental Health programs in BC. It is certain that this will be an exciting season in the BC Branch and for CIPHI.

\section{Manitoba Branch Darcy Chrisp President, CIPHI MB Branch}

Spring has finally sprung, although we cannot really complain about the past winter as it was unseasonably bearable. Not only has the weather warmed up, but public health inspection programming in Manitoba has been boosted by the addition of 18 Public Health Inspectors from the City of Winnipeg who were officially transferred to the Province of Manitoba as of April 1st. Those of us working for the province are very excited to welcome our colleagues from the City of Winnipeg and we look forward to building a cohesive provincial program.

The Manitoba Branch is gearing up for our spring workshop scheduled for May 31st at the Viscount Gort in Winnipeg. We have lined up several exciting speakers to educate us on such topics as Lyme disease, Radon testing in well water, and food safety. The event will conclude with our annual AGM and Branch Elections.

The Manitoba Branch Website has undergone a complete overhaul in the last few months. Our Webmaster, Carmen 
Cross, has put in several hours re-tooling the website and it can be viewed at www.ciphi.mb.ca. Thanks to Carmen for her fantastic efforts on this project.

I would like to close by thanking Melanie Cyrenne and Natalie Lowdon who plan to step down from the Branch Executive at the end of their terms in May. Both have been instrumental in moving our Branch forward in the last four years and I appreciate the time they gave to the Branch Executive.

I wish everyone a great summer and hope to see many of you in Blue Mountains, Ontario at the National Educational Conference in September.

\section{Newfoundland and Labrador Branch Darroch Vokey}

President, CIPHI Newfoundland and Labrador Branch

Greetings from Newfoundland and Labrador. Our Branch membership continues to grow, and our provincial executive is working diligently to recruit both active and retired EHO's to CIPHI.

On the provincial scene, our executive is actively promoting our profession and the benefits and advantages that CIPHI offers in terms of professional development. The NL branch is researching and assessing our status and ability to host the 2014 Annual Educational Conference. We hope to have some positive news for our national executive in the near future.

As the new NL Branch President, I am proud and most enthusiastic about interactions with my provincial counterparts from all across Canada. It has been a rewarding and pleasant ride on the learning curve, and I am most appreciative of the warm reception I have received during this endeavour.

I am looking forward to seeing many friends and colleagues at the AEC in Blue Mountains this year.

\section{Ontario Branch \\ Ken Diplock \\ President, CIPHI Ontario Branch}

2012 is shaping up to be an exciting year for CIPHI Ontario. We are excited to be working with the Grey Bruce and Simcoe Muskoka District Health Units to host the 78th Annual CIPHI Educational Conference from September 16 to 19, 2012, at The Village at Blue Mountain Conference Centre located in the Town of the Blue Mountains, Ontario.

Chris Munn and Ted Devine - directors and co-chairs of the hosting partnership between the two health units - tell us the collaboration has been both an exciting and challenging opportunity and it has certainly eased the effort needed to put on a national event by sharing both the workload and the valuable experience gained by staff.

The Educational Conference will provide opportunities for delegates to attend sessions and workshops on a variety of topics that reflect the theme of Healthy Places, Healthy People and includes the program streams Link, Learn, and Lead. Of course, conference attendance will also earn you valuable professional development hours to apply to your CIPHI Continuing Professional Competencies annual profile.

The conference planning committee has been working diligently to deliver an exciting, entertaining and educational conference. They have secured three dynamic key note speakers:

- Dr. David Butler-Jones, Chief Public Health Officer, Public Health Agency of Canada

- Holly Dressel, Best Selling Author and Environmental and Health Care Researcher, Adjunct Professor at McGill University

- Meg Soper, Motivational Speaker and Humourist

The Conference also provides a great opportunity to network with other public health inspectors and public health professionals. After the lectures and workshops you can enjoy the Town of Blue Mountains with its wonderful culinary venues and amazing scenery. The conference social programs will offer opportunities to reconnect with peers and forge new contacts and partnerships.

In addition to a Welcome Reception, President's Banquet and a Blue Mountain Village "Passport Event", there will be a Golf Tournament sponsored and organized by the Environmental Health Foundation. Registration fees for the pre-conference Golf Tournament are not included with the conference registration. For more information about the tournament, visit their Facebook event page CIPHI 2012 Golf Tournament.

Detailed information including registration forms and speaker bios are available through the CIPHI Conference website. The webpage will be periodically updated throughout the spring and summer.

Start planning to attend now, register early to take advantage of early bird pricing and see you all there.

\section{Saskatchewan Ryan Philipation President, CIPHI SK Branch}

On behalf of the SK Branch, I submit the following report outlining our recent branch activities.

I was recently told by a member that they are proud to be part of this group of Public Health Professionals and CIPHI. As I reflect on those comments, it reminds me of my own feeling that CIPHI is great! Our history is rich and our future is bright. As we move toward celebrating the centennial year, it is a great time to get active with your branch or national committee to help mark this significant milestone.

The SK Branch has been busy since the last update. The Branch has recently developed the SK Branch Historian position. Wayne Johnson has accepted the position and will begin reviewing SK Branch archives. I am excited to see this important position develop as it will benefit both our SK Branch and our national historical initiatives.

The Branch continues to develop the partnership with First Nations University. The annual student pizza night was held in February. The evening was a great success as Environmental Health students had the opportunity to interact with many members of the Executive. A special thanks to Councilor Verna Law for organizing the event. The Executive will continue to engage these students in an effort to heighten their knowledge and interest in CIPHI. 
Work has also begun on the 5th Annual Professional Education and Development Seminar. This great seminar will be held in Saskatoon on November 14 and 15, 2012. It continues to grow and is the biggest annual event in Saskatchewan directed at Public Health Inspectors. As usual with branch business, it's the volunteers who make this event successful. Members are encouraged to attend this event as it provides an excellent opportunity for professional development and networking with industry experts and colleagues.

On behalf of the SK Branch, I would like to take this opportunity to thank Michael McCann for once again organizing the April BOC Exams in Saskatchewan. Michael continues to work tirelessly in various capacities for the SK Branch. His positive volunteer attitude is admirable and motivating for many on the current Executive. 